\title{
STUDY ON SHORT-TERM CREEP EFFECT AND HYSTERESIS FOR THE HBM Z4A FORCE TRANSDUCER UNDER COMPRESSIVE AND TENSILE FORCES
}

\author{
J. Fidelus ${ }^{1}$, K. Cybul ${ }^{2}$ \\ ${ }^{1}$ GUM, Central Office of Measures, 00139 Warsaw, Poland, janusz.fidelus@gum.gov.pl \\ ${ }^{2}$ GUM, Central Office of Measures, 00139 Warsaw, Poland, kamil.cybul@gum.gov.pl
}

\begin{abstract}
:
The results of creep tests (for compressive and tensile forces) for the HBM Z4A force transducer made in a Force Standard Machine (FSM) working in the range from $1 \mathrm{kN}$ to $55 \mathrm{kN}$ in the Central Office of Measures are described. Studies have shown that the largest indications of the force transducer (given in electrical units, $\mathrm{mV} / \mathrm{V}$ ) in the first seconds of testing are most likely due to the mechanical properties of the materials from which the transducer is built. Higher values of relative hysteresis error and relative measurement uncertainty were observed for the compressive forces.
\end{abstract}

Keywords: force; metrological traceability chain; creep; force transducer; calibration; hysteresis

\section{INTRODUCTION}

The currently-available traceability chain covers only uniaxial static forces, applied perfectly, at constant temperature, to test specimens that react in a purely axisymmetric manner. This is not how systems perform in practice, where there are additional effects due to short term creep, hysteresis, temperature, data synchronisation, instrumentation, alignment and non-axial force application [1]. The purpose of this work is to examine the effect of short-term creep and hysteresis for a selected force transducer subjected to compressive and tensile forces.

\section{CREEP AND HYSTERESIS STUDIES}

\subsection{Experimental Conditions}

\section{Calibrated Object}

The force-proving instrument comprised the force transducer and measuring amplifier, both manufactured by HBM, Germany, and the HBM Catman software for data archiving and analysis.

Force transducer characteristics:

- maximum capacity $50 \mathrm{kN}$
- for compressive and tensile forces

- type Z4A

- $\quad$ serial number 90330092

- temperature coefficient $K=0.000015^{\circ} \mathrm{C}^{-1}$

Measuring amplifier characteristics:

- type DMP41-T2

- $\quad$ serial number 819192401

- resolution $0.000001 \mathrm{mV} / \mathrm{V}$

- channel 1

- filter $0.10 \mathrm{~Hz}$ and $1 \mathrm{~Hz}$ Bessel, measuring range $\pm 2.5 \mathrm{mV} / \mathrm{V}$, excitation voltage $5 \mathrm{~V}$

\section{Environmental Conditions}

Ambient temperature for compressive forces: (22.8 to 23.7 ) ${ }^{\circ} \mathrm{C} \pm 0.1{ }^{\circ} \mathrm{C}$ and tensile forces: (24.1 to 24.8$){ }^{\circ} \mathrm{C} \pm 0.1{ }^{\circ} \mathrm{C}$.

\section{Traceability}

Calibration results of the force-proving instrument have been referred to the force reference standard maintained at the Central Office of Measures through application of the force standard machine no. S03 (WS-55 kN), covering the force range from $1 \mathrm{kN}$ up to $55 \mathrm{kN}$, with the uncertainty of applied force $0.01 \%$ of the measured value.

Creep measurement (compressive and tensile forces) for the Z4A force transducer of the HBM company with a measuring range up to $50 \mathrm{kN}$ and sensitivity of $2 \mathrm{mV} / \mathrm{V}$, was carried out at the GUM's FSM working in the range of $1 \mathrm{kN}$ to $55 \mathrm{kN}$ (WS-55 kN), see Figure 1.

Due to the inability to determine the stiffness of the measuring system, the measurement of the indication of the force transducer was carried out electrically, in $\mathrm{mV} / \mathrm{V}$ units, using the DMP41-T2 measuring amplifier of the HBM company (with a $0.1 \mathrm{~Hz}$ Bessel digital filter), which has the best accuracy class and resolution of $1 \mathrm{ppm}$ in the measuring range of $\pm 2.5 \mathrm{mV} / \mathrm{V}$. In order to verify the correctness of the results (the appropriate number of measuring points), the tests were also carried out using digital filters of higher frequencies. Tests for compressive and tensile 
forces were carried out in accordance with the PN-EN ISO 376:2011 standard [2].

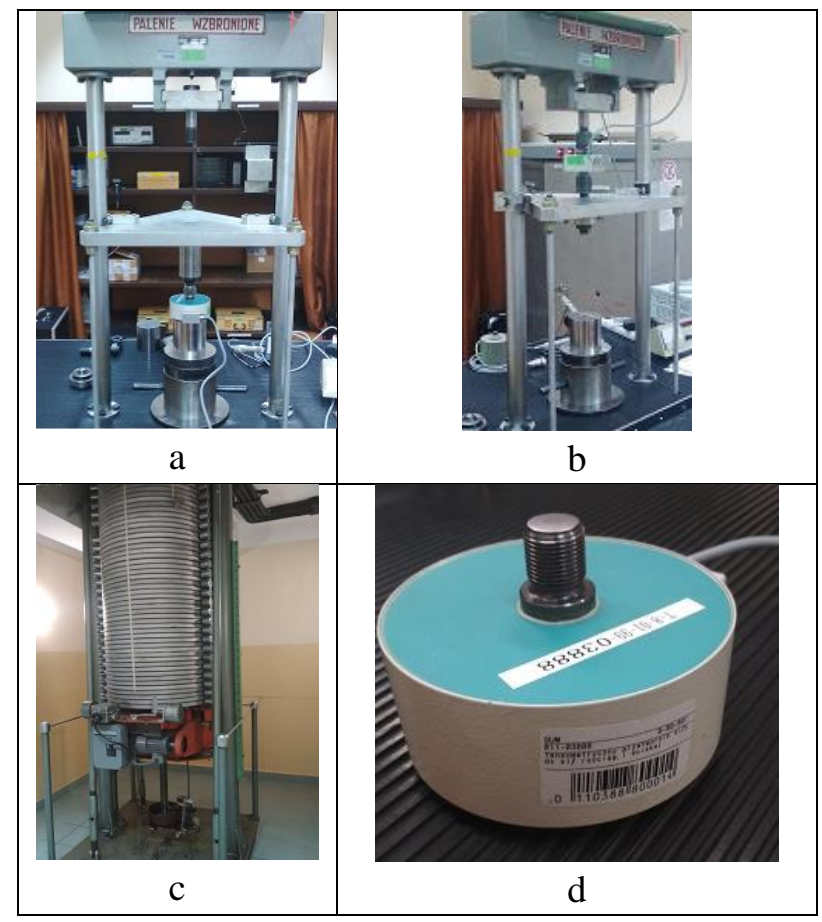

Figure 1: GUM's force reference standard maintained at the Central Office of Measures through application of the force standard machine No. S03 (WS-55 kN), covering the force range from $1 \mathrm{kN}$ up to $55 \mathrm{kN}$, with the uncertainty of applied force $0.01 \%$ of the measured value: a) upper part: FSM with mounted force transducer prepared for compressive test; b) upper part: FSM with mounted force transducer prepared for tension test; c) FSM - lower part; d) HBM Z4A force transducer

\subsection{Creep Study}

Due to the elastic effect of the HBM Z4A force transducer components (elastic material and strain gauges), there are slight changes in the output signal with constant force caused by creep. This effect is essential not only in long measurements, where the low creep value is very important, but also in shortterm measurements. Creep error may be affected by, among others, design of the force transducer and elements of which it is built, used force transducer electric cable, measuring meter, measurement axis and construction of the reference station itself.

With increasing the temperature, creep of steel and strain gauges increases. The indication creeping may also be caused by temperature gradients causing uneven thermal deformation of the elastic element. Therefore, it is important to ensure that the temperature of the transducer and its surroundings during the measurement is the same and constant.

In order to accurately measure creep, the number of measuring points in the first thirty seconds of the test after applying the maximum reference force and after removing the maximum reference force has been increased (compared to those applicable in the PN-EN ISO 376:2011 standard). The indication in $\mathrm{mV} / \mathrm{V}$ was measured every $1 \mathrm{~s}$ in the first $30 \mathrm{~s}$ and every $60 \mathrm{~s}$ in the period from $60 \mathrm{~s}$ to $300 \mathrm{~s}$. Figure 2 shows a graph of force as a function of time in the direction of tensile and compressive forces in accordance to ISO 376:2011 standard with creep test. After the initial load $(3 \times 60 \mathrm{~s})$, the actual measurement was carried out. The light brown colour shows the tested creep ranges. The relative zero indication error is $0.001 \%$ of the maximum reference force. The relative interpolation error was determined in accordance with the PN-EN ISO 376:2011 standard.



Figure 2: Calibration of the Z4A force transducer in the direction of tensile and compressive forces in accordance to ISO 376:2011 standard with creep test. The light brown colour shows the tested creep ranges

\section{Tensile Forces}

The metrological characterization of the $\mathrm{Z4A}$ force transducer for the tensile forces presents Table 1. Each time the creep was tested at the beginning and at the end of the measurement series. The creep measurement was carried out after the initial (preliminary) loads, after applying the maximum reference force (Figure 2a and Figure 3) and after removing the maximum reference force, which was maintained for $300 \mathrm{~s}$ (Figure $2 \mathrm{~b}$ and Figure 4). Figure 3 shows the indication of the Z4A force transducer (in $\mathrm{mV} / \mathrm{V}$ ) after applying the maximum reference force $F_{\max }$. The insert represents the creep in the first $10 \mathrm{~s}$ of the measurement. The error was determined in accordance to ISO 376:2011standard. In the third second you can see the change in the direction of the plot. In the case of removing the force (after previously applying $F_{\max }$ for $90 \mathrm{~s}$ ), you can see increasing of the creep (Figure 4). The maximum creep error can be observed in the first three seconds.

The relative interpolation error $f_{\mathrm{c}}$ was determined using a cubic equation of deflection as a function of the calibration force $F$ :

$$
\begin{array}{rl}
X_{\mathrm{a}}=-3.996 & 42 \times 10^{-2} F \\
& -3.1152 \times 10^{-7} F^{2} \\
& -8.43 \times 10^{-10} F^{3} .
\end{array}
$$


Table 1: Metrological characteristic and measurement uncertainty of the Z4A force transducer for the tensile forces. Zero reading of the transducer: $0.000938 \mathrm{mV} / \mathrm{V}$ taken after the last measuring series, without any loading fittings

\begin{tabular}{|c|c|c|c|c|c|c|c|c|}
\hline $\begin{array}{c}\text { Calibration } \\
\text { force }\end{array}$ & $\begin{array}{c}\text { Average } \\
\text { value of } \\
\text { deflection } \\
\overline{\boldsymbol{X}_{\mathbf{r}}}\end{array}$ & $\begin{array}{c}\text { Relative } \\
\text { repeatability } \\
\text { error } \\
\boldsymbol{b}^{\prime}\end{array}$ & $\begin{array}{c}\text { Relative } \\
\text { reproducibility } \\
\text { error } \\
\boldsymbol{b}\end{array}$ & $\begin{array}{c}\text { Relative } \\
\mathbf{c r e e p} \\
\text { error } \\
\boldsymbol{c}\end{array}$ & $\begin{array}{c}\text { Computed } \\
\text { value of } \\
\text { deflection } \\
\boldsymbol{X}_{\mathbf{a}}\end{array}$ & $\begin{array}{c}\text { Relative } \\
\text { interpolation } \\
\text { error } \\
\boldsymbol{f}_{\mathbf{c}}\end{array}$ & $\begin{array}{c}\text { Relative } \\
\text { measurement } \\
\text { uncertainty } \\
\boldsymbol{W}\end{array}$ & $\begin{array}{c}\text { (lass } \\
\text { Cla }\end{array}$ \\
\hline 1 & -0.039963 & 0.010 & 0.008 & - & -0.039965 & -0.004 & 0.019 & 00 \\
\hline 2 & -0.079930 & 0.005 & 0.008 & - & -0.079930 & 0.000 & 0.016 & 00 \\
\hline 5 & -0.199832 & 0.001 & 0.013 & - & -0.199829 & 0.001 & 0.014 & 00 \\
\hline 10 & -0.399677 & 0.000 & 0.008 & - & -0.399674 & 0.001 & 0.013 & 00 \\
\hline 15 & -0.599536 & 0.000 & 0.005 & - & -0.599536 & 0.000 & 0.013 & 00 \\
\hline 20 & -0.799414 & 0.000 & 0.004 & - & -0.799415 & 0.000 & 0.013 & 00 \\
\hline 25 & -0.999311 & 0.000 & 0.003 & - & -0.999313 & 0.000 & 0.013 & 00 \\
\hline 30 & -1.199228 & 0.000 & 0.003 & - & -1.199229 & 0.000 & 0.012 & 00 \\
\hline 35 & -1.399166 & 0.000 & 0.005 & - & -1.399165 & 0.000 & 0.012 & 00 \\
\hline 40 & -1.599122 & 0.000 & 0.005 & - & -1.599120 & 0.000 & 0.012 & 00 \\
\hline 45 & -1.799099 & 0.000 & 0.005 & - & -1.799097 & 0.000 & 0.012 & 00 \\
\hline 50 & -1.999092 & 0.000 & 0.005 & 0.002 & -1.999094 & 0.000 & 0.012 & 00 \\
\hline
\end{tabular}

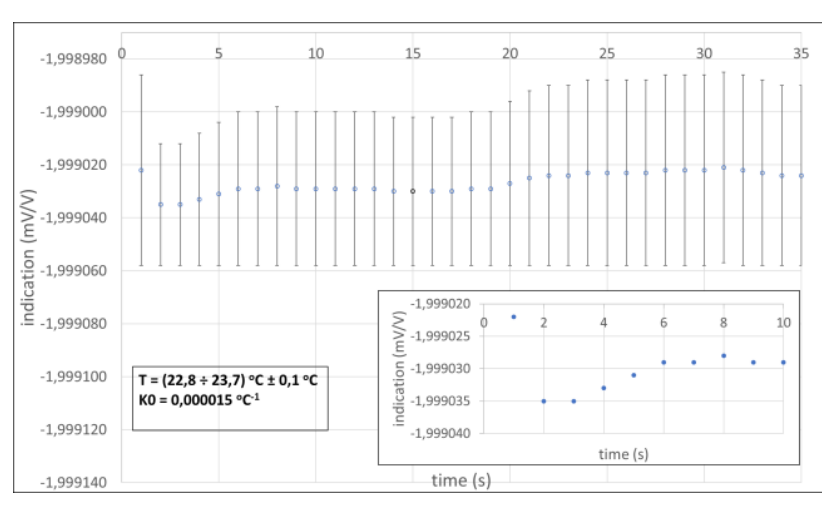

Figure 3: Graph of Z4A force transducer indication given in electrical units $(\mathrm{mV} / \mathrm{V})$ in the time function $(\mathrm{s})$ for measurements made after applying the maximum tension reference force. The insert represents the creep in the first $10 \mathrm{~s}$ of the measurement. For the sake of clarity, there are no error bars.

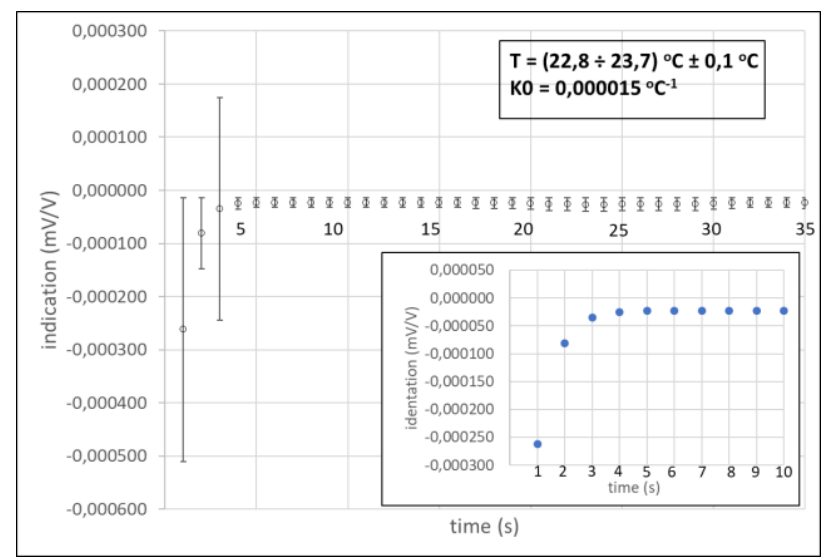

Figure 4: Graph of Z4A force transducer indication given in electrical units $(\mathrm{mV} / \mathrm{V})$ in the time function $(\mathrm{s})$ for measurements made after removing the maximum tension reference force $(90 \mathrm{~s})$. The insert represents the creep in the first $10 \mathrm{~s}$ of the measurement
Coefficients of this function were determined from average values of deflection $\bar{X}_{\mathrm{r}}$ using the method of least squares.

The inverse function of the above is used to calculate force $F_{\text {a }}$ from the deflection $X$ :

$$
\begin{gathered}
F_{\mathrm{a}}=-25.022394 X-4.88231 \times 10^{-3} X^{2} \\
+3.27176 \times 10^{-4} X^{3}
\end{gathered}
$$

Symbols and their meanings:

$X_{\mathrm{a}}=$ computed value of deflection of the force-proving instrument corresponding to any force $F$

$F=$ calibration force

$F_{\mathrm{a}}=$ computed value of calibration force reproduced by the force-proving instrument, calculated for any value of deflection $X$ $X=$ deflection with increasing force

The relative uncertainty of measurement $W$, expressed as a percentage, is dependent on force $F$ (in units of $\mathrm{kN}$ ) and defined by equation (3).

$W=2 \times\left(C_{0}+\frac{C_{1}}{F}\right)$

where:

$C_{0}=5.868 \times 10^{-3}$

$C_{1}=3.536 \times 10^{-3}$ 
Table 2: Metrological characteristic and measurement uncertainty of the Z4A force transducer for the compressive forces. Zero reading of the transducer: $-0.000150 \mathrm{mV} / \mathrm{V}$ taken after the last measuring series, without any loading fittings

\begin{tabular}{|c|c|c|c|c|c|c|c|c|}
\hline $\begin{array}{c}\begin{array}{c}\text { Calibration } \\
\text { force }\end{array} \\
F \\
\end{array}$ & $\begin{array}{c}\text { Average } \\
\text { value of } \\
\text { deflection } \\
\overline{X_{\mathrm{r}}} \\
\end{array}$ & $\begin{array}{c}\text { Relative } \\
\text { repeatability } \\
\text { error } \\
b^{\prime} \\
\end{array}$ & $\begin{array}{c}\text { Relative } \\
\text { reproducibility } \\
\text { error } \\
b \\
\end{array}$ & $\begin{array}{c}\text { Relative } \\
\text { creep } \\
\text { error } \\
c \\
\end{array}$ & $\begin{array}{c}\text { Computed } \\
\text { value of } \\
\text { deflection } \\
X_{\mathrm{a}} \\
\end{array}$ & $\begin{array}{c}\text { Relative } \\
\text { interpolation } \\
\text { error } \\
\boldsymbol{f}_{\mathrm{c}} \\
\end{array}$ & $\begin{array}{c}\text { Relative } \\
\text { measurement } \\
\text { uncertainty } \\
W \\
\end{array}$ & Class \\
\hline $\mathrm{kN}$ & $\mathrm{mV} / \mathrm{V}$ & $\%$ & $\%$ & $\%$ & $\mathrm{mV} / \mathrm{V}$ & $\%$ & $\%$ & \\
\hline 1 & 0.039970 & 0.005 & 0.030 & - & 0.039967 & 0.007 & 0.027 & 00 \\
\hline 2 & 0.079935 & 0.000 & 0.021 & - & 0.079934 & 0.000 & 0.020 & 00 \\
\hline 5 & 0.199830 & 0.002 & 0.018 & - & 0.199833 & -0.001 & 0.016 & 00 \\
\hline 10 & 0.399658 & 0.001 & 0.012 & - & 0.399657 & 0.000 & 0.014 & 00 \\
\hline 15 & 0.599475 & 0.001 & 0.010 & - & 0.599474 & 0.000 & 0.014 & 00 \\
\hline 20 & 0.799283 & 0.001 & 0.007 & - & 0.799284 & 0.000 & 0.013 & 00 \\
\hline 25 & 0.999090 & 0.001 & 0.006 & - & 0.999090 & 0.000 & 0.013 & 00 \\
\hline 30 & 1.198894 & 0.000 & 0.006 & - & 1.198892 & 0.000 & 0.013 & 00 \\
\hline 35 & 1.398692 & 0.000 & 0.006 & - & 1.398692 & 0.000 & 0.013 & 00 \\
\hline 40 & 1.598489 & 0.000 & 0.006 & - & 1.598491 & 0.000 & 0.013 & 00 \\
\hline 45 & 1.798289 & 0.000 & 0.006 & - & 1.798290 & 0.000 & 0.013 & 00 \\
\hline 50 & 1.998092 & 0.000 & 0.005 & 0.001 & 1.998091 & 0.000 & 0.013 & 00 \\
\hline
\end{tabular}

\section{Compressive Forces}

In the case of compression forces, the metrological characteristic of the Z4A force transducer is included in Table 2. As for the tensile forces, the relative interpolation error $f_{\mathrm{c}}$ was determined using cubic equation of deflection as a function of the calibration force $F$ :

$$
\begin{array}{rl}
X_{\mathrm{a}}=-3.996 & 76 \times 10^{-2} \mathrm{~F} \\
& -2.05013 \times 10^{-7} F^{2} \\
& +1.792 \times 10^{-9} F^{3}
\end{array}
$$

while $F_{\mathrm{a}}$ depends on the deflection $X$ and is given by equation (5).

$$
\begin{gathered}
F_{\mathrm{a}}=25.020267 X+3.21218 \times 10^{-3} X^{2} \\
-7.02567 \times 10^{-4} X^{3} .
\end{gathered}
$$

The relative uncertainty of measurement $W$ (in \%) is dependent on force $F$ (in units of $\mathrm{kN}$ ) and defined by equation (3), with $C_{0}=6.114 \times 10^{-3}$ and $C_{1}=7.101 \times 10^{-3}$.

The creep measurement was performed after the last measurement series in accordance with Figure 2.

Figure 5 presents a graph of the force transducer indication dependence (given in electrical units, $\mathrm{mV} / \mathrm{V}$ ) as a function of time for measurements made after applying the maximum reference force, while Figure 6 illustrates a similar relationship after removing the maximum reference force.

For both measurements, a decrease in the relative creep error value as a function of time can be observed. This error is the largest in the first minute of testing. The higher indication values of the force transducer (given in $\mathrm{mV} / \mathrm{V}$ ) in the first seconds of testing are mainly due to the mechanical properties of the materials it is made of. Studies have shown the difference in the relative creep error size for creep measurements after applying the maximum reference force, and the measurements after removing the maximum compressive reference force. Higher (by order of magnitude) values of relative creep error occur after removing the maximum reference force.

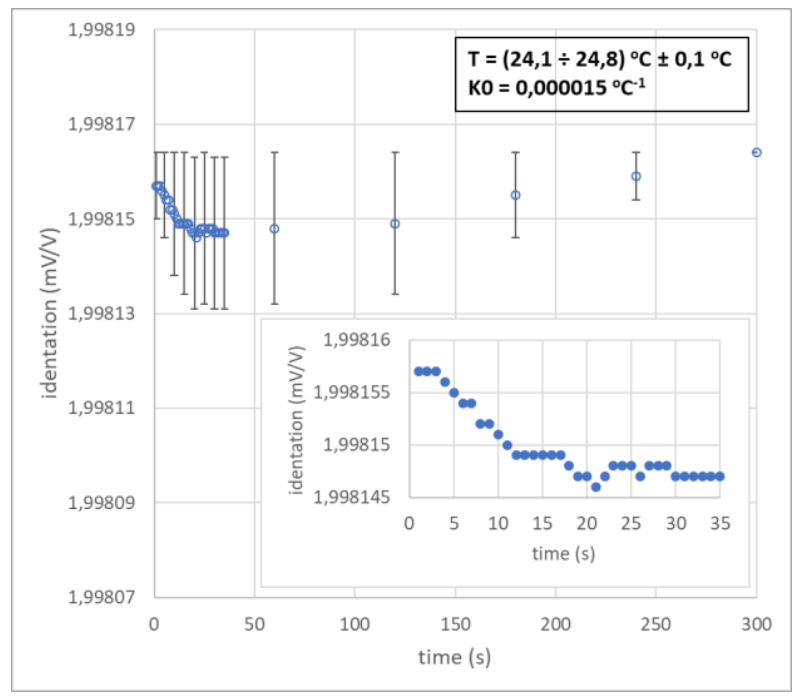

Figure 5: Graph of Z4A force transducer indication given in electrical units $(\mathrm{mV} / \mathrm{V})$ in the time function $(\mathrm{s})$ for measurements made after applying the maximum compressive reference force. The insert represents the creep in the first $35 \mathrm{~s}$ of the measurement

\subsection{Hysteresis Study}

It is known that the indications of a transducer at a given force depend on its loading history. The measuring hysteresis of the $\mathrm{Z4A}$ force transducer may include the following reasons:

- hysteresis of an elastic element conditioned by internal friction, slips and permanent deformations of the material of the element

- friction and play in mechanisms converting deformation to indication, i.e. in levers, bearings, etc. 
- friction between the measuring elements, the transducer housing, seals and membranes and their fixing places

- friction on boundary surfaces

- elastic hysteresis of strain gauges, washers, glue and electric cables

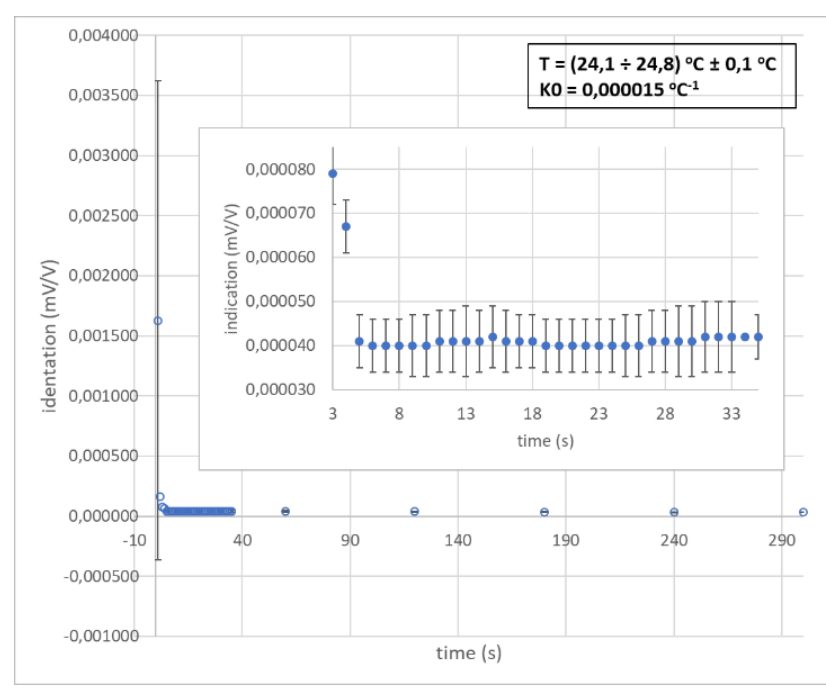

Figure 6: Graph of Z4A force transducer indication given in electrical units $(\mathrm{mV} / \mathrm{V})$ in the time function $(\mathrm{s})$ for measurements made after removing the maximum compressive reference force (90 s). The insert represents the creep in the first $35 \mathrm{~s}$ of the measurement
During the calibration of the Z4A transducer, measurement hysteresis errors were determined for each of the applied load, defined as the difference between the indications obtained with the same force, achieved with a load increasing from zero and decreasing from the upper limit of the measuring range (Table 3). Figure 7 shows the dependence of the relative hysteresis error and the relative measurement uncertainty (insert) on the calibrated force (compressive and tensile forces) for the Z4A force transducer.

In the range of up to $5 \mathrm{kN}$, higher values of relative hysteresis error and relative measurement uncertainty were recorded for the compressive forces, while in the range from $5 \mathrm{kN}$ to $30 \mathrm{kN}$ higher values of hysteresis errors were observed for the tensile forces.

\section{SUMMARY}

The results of creep tests at maximum studied force and after force removal in accordance to ISO 376:2011 for the HBM Z4A force transducer made on the GUM's force reference standard machine up to $55 \mathrm{kN}$ (WS-55 kN) no. S03, covering the force range from $1 \mathrm{kN}$ up to $55 \mathrm{kN}$, with the uncertainty of applied force $0.01 \%$ of the measured value were presented. The short-term creep effect of the HBM Z4A force transducer was investigated.

Table 3: Relative hysteresis error and measurement uncertainty of the Z4A force transducer for tensile and compressive forces

\begin{tabular}{|c|c|c|c|c|c|c|}
\hline \multirow{2}{*}{$\begin{array}{c}\text { Calibration } \\
\text { force }\end{array}$} & \multicolumn{3}{|c|}{ Tensile forces } & \multicolumn{3}{|c|}{ Compressive forces } \\
\cline { 2 - 3 } & $\begin{array}{c}\text { Relative } \\
\text { hysteresis } \\
\text { error } \\
\boldsymbol{v}\end{array}$ & $\begin{array}{c}\text { Relative } \\
\text { measurement } \\
\text { uncertainty } \\
\boldsymbol{W}\end{array}$ & \multirow{2}{*}{ Class } & $\begin{array}{c}\text { Relative } \\
\text { hysteresis } \\
\text { error } \\
\boldsymbol{v}\end{array}$ & $\begin{array}{c}\text { Relative } \\
\text { measurement } \\
\text { uncertainty } \\
\boldsymbol{W}\end{array}$ & Class \\
\cline { 5 - 7 } & $\%$ & $\%$ & & $\%$ & $\%$ & \\
\hline $\mathrm{kN}$ & 0.068 & 0.035 & 00 & 0.080 & 0.044 & 0,5 \\
\hline 1 & 0.044 & 0.025 & 00 & 0.057 & 0.029 & 00 \\
\hline 2 & 0.033 & 0.019 & 00 & 0.034 & 0.020 & 00 \\
\hline 5 & 0.027 & 0.017 & 00 & 0.023 & 0.017 & 00 \\
\hline 10 & 0.022 & 0.016 & 00 & 0.019 & 0.016 & 00 \\
\hline 15 & 0.019 & 0.016 & 00 & 0.015 & 0.016 & 00 \\
\hline 20 & 0.015 & 0.015 & 00 & 0.012 & 0.016 & 00 \\
\hline 25 & 0.012 & 0.015 & 00 & 0.009 & 0.015 & 00 \\
\hline 30 & 0.009 & 0.015 & 00 & 0.007 & 0.015 & 00 \\
\hline 35 & 0.006 & 0.015 & 00 & 0.004 & 0.015 & 00 \\
\hline 40 & 0.003 & 0.015 & 00 & 0.002 & 0.015 & 00 \\
\hline 45 & - & 0.015 & 00 & - & 0.015 & 00 \\
\hline 50 & & & & & \\
\hline
\end{tabular}




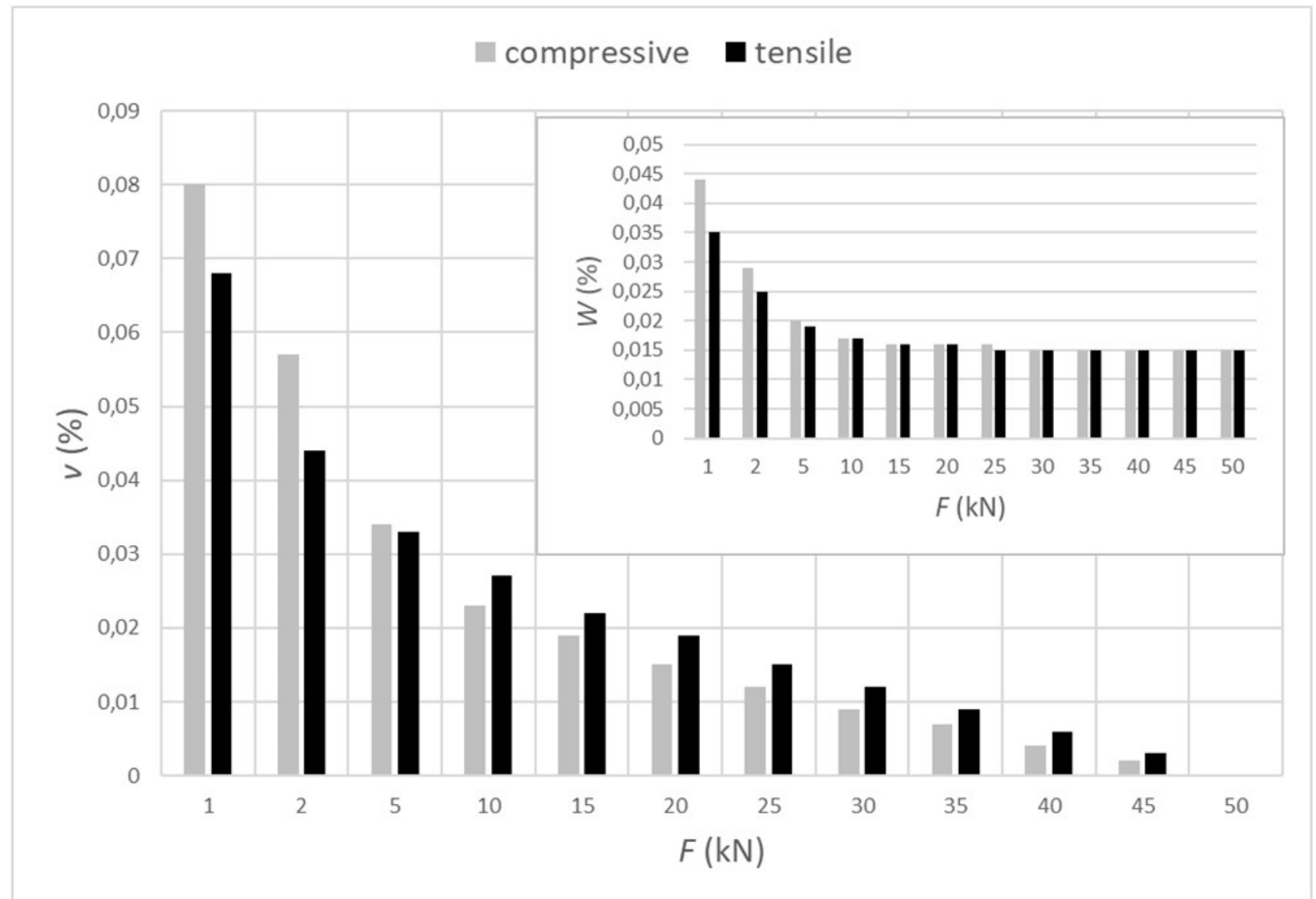

Figure 7: Calibration force versus relative hysteresis error for the Z4A force transducer after applying tensile and compressive forces. The insert represents the plot of the calibration force versus relative measurement uncertainty for the transducer after applying tensile and compressive forces

Studies have shown that the largest indications of the force transducer (given in electrical units, $\mathrm{mV} / \mathrm{V}$ ) in the first seconds of testing are most likely due to the mechanical properties of the materials from which the transducer is built. In the range of up to $5 \mathrm{kN}$, higher values of relative hysteresis error and relative measurement uncertainty were recorded for the compressive forces, while in the range from $5 \mathrm{kN}$ to $30 \mathrm{kN}$ higher values of errors and uncertainty were observed for the tensile forces. The performed calibration of the Z4A force transducer in the measuring range from $1 \mathrm{kN}$ to $50 \mathrm{kN}$ for tensile forces confirmed its Class 00 for both creep and hysteresis. In the future, similar studies are planned on other HBM Z4/Z4A transducers to see if they exhibit comparable behaviour.

\section{ACKNOWLEDGEMENTS}

This work has been carried out in the framework of the EMPIR Joint Research Project 18SIB08 'Force' with the title "Comprehensive traceability for force metrology services", ComTraForce for 2019 - 2023. The EMPIR is jointly funded by the EMPIR participating countries within EURAMET and the European Union.


\section{REFERENCES}

[1] Website of the EMPIR project "Comprehensive traceability for force metrology services", 18 SIB08 ComTraForce:

https://www.ptb.de/empir2019/comtraforce/project/o verview/

[2] PN-EN ISO 376:2011 standard "Metallic materials Calibration of force-proving instruments used for the verification of uniaxial testing machines". 